\title{
OPTICS FOR A PHOTOINJECTED ENERGY RECOVERY LINAC AT THE NSLS
}

\author{
$\underline{\text { V. Yakimenko }}^{\dagger}$, I. Ben-Zvi, J.B. Murphy, S. Pjerov, J.H. Wu, \\ BNL, Upton, NY 11973 USA
}

\section{Abstract}

The Photoinjected Energy Recovery Linac (PERL) design study at the NSLS [1] is considering the feasibility of a new synchrotron light source based on a 3-7 GeV energy recovering superconducting linac injected by a laser photocathode RF gun (photoinjector). In addition to returning the electron beam to the linac with a phase shift of 180 degrees, the "return loop" of the PERL must be capable of longitudinal bunch compression, minimize the deleterious effects of coherent synchrotron radiation and provide space for up to two-dozen insertion devices. We present a design for the PERL optics based on tuneable achromats.

\section{INTRODUCTION}

We can logically split the machine into three stages: injector, low energy loop and full energy loop. The injector includes RF gun and linac that boost the energy of the beam to $25 \mathrm{MeV}$. We do not consider energy recovery for this stage. The low energy loop consists of a booster linac with harmonic cavities to bring the beam energy to $300 \mathrm{MeV}$ and compensate for nonlinearity of the longitudinal phase space due to RF curvature and other sources. Arcs in that loop act as a compressor (decompressor for return pass). The low energy loop allows us to reduce ratio of initial to final beam energy in the main linac and naturally add an additional compression stage. The full energy loop consists of the main linac, two arcs and a long straight section. We plan to have a $3 \mathrm{GeV} 100 \mathrm{fs}$ beam in the long $(50 \mathrm{~m})$ insertion device. Each arc consists of 12 cells, with space for a total of 23 insertion devices.

There are three major points of the optical design that we present in this document. First is focusing in the linacs, second - use of the triple bend achromats [2],[3] to compress the beam and to produce zero dispersion drifts for insertion devices and lastly - use of arcs to compress beam in two stages down to $100 \mathrm{fs}$.

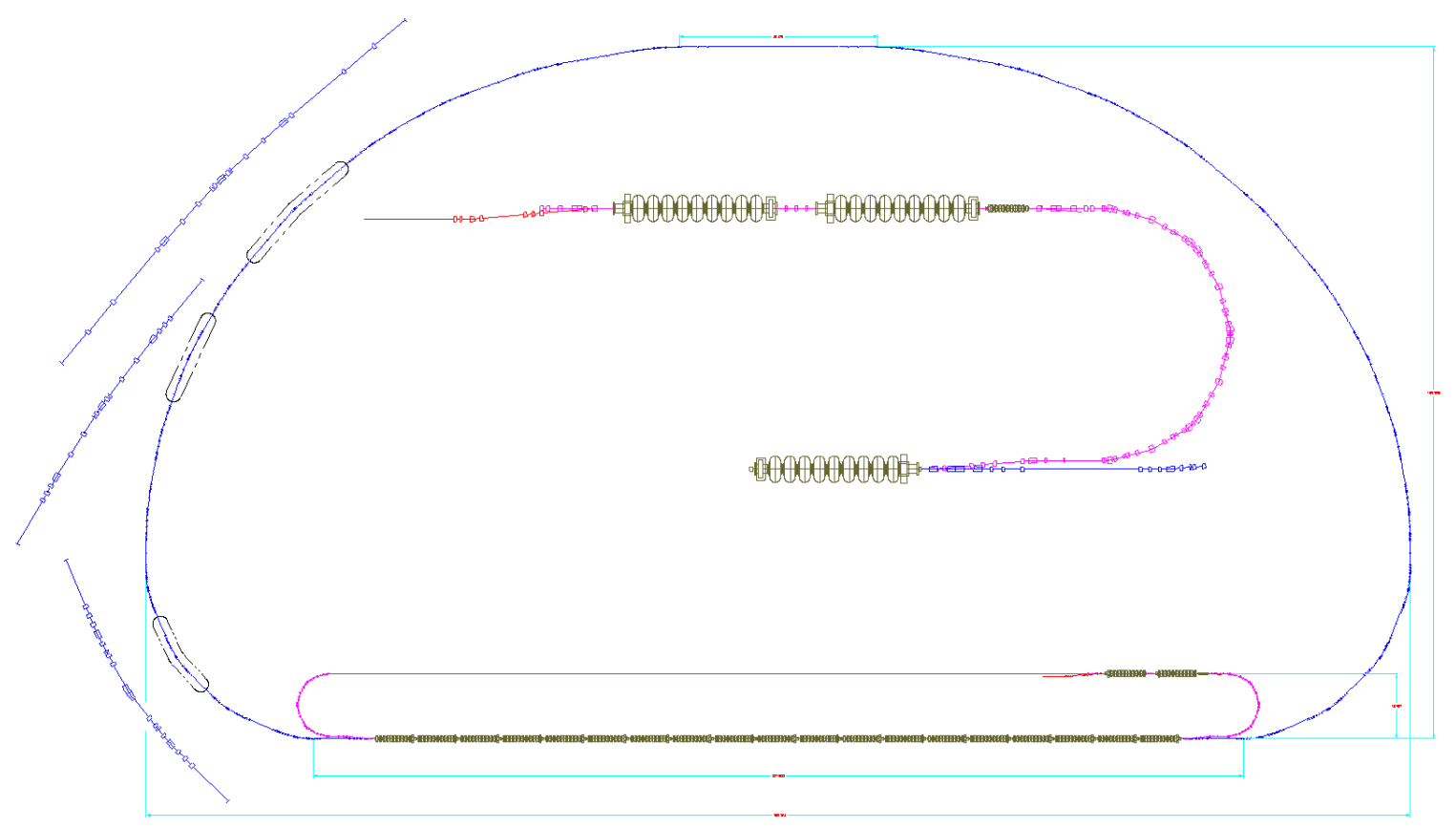

Figure 1 Proposed layout for a photoinjected energy recovery linac at the NSLS

\footnotetext{
* Under contract with the United States Department of Energy, Contract Number DE-AC02-98CH10886

†vakimenko@bnl.gov
} 


\section{OPTICAL SOLUTIONS IN THE LINAC}

We plan to use single triplet focusing in the middle of the low energy linac. Both accelerated and decelerated beams would have approximately same energy in the triplet location and would see the same focusing. The harmonic cavities that improve the linearity of the longitudinal phase space will be installed in the middle as well. That design works for the low energy linac because its overall length is relatively short. We suggest using the usual FODO focusing for the main $200 \mathrm{~m}$ long linac with $10 \mathrm{~m}$ long accelerating sections. All quadrupole have the same strength and as FODO type of focusing offers the least energy dependence as compared to doublet or triplet focusing schemes. We achieved uniform growth (for the acceleration path, and the opposite for deceleration) of the $\beta$-functions over the length of the linac and nearly constant beam sizes in the linac as the emittance is reduced due to adiabatic damping.

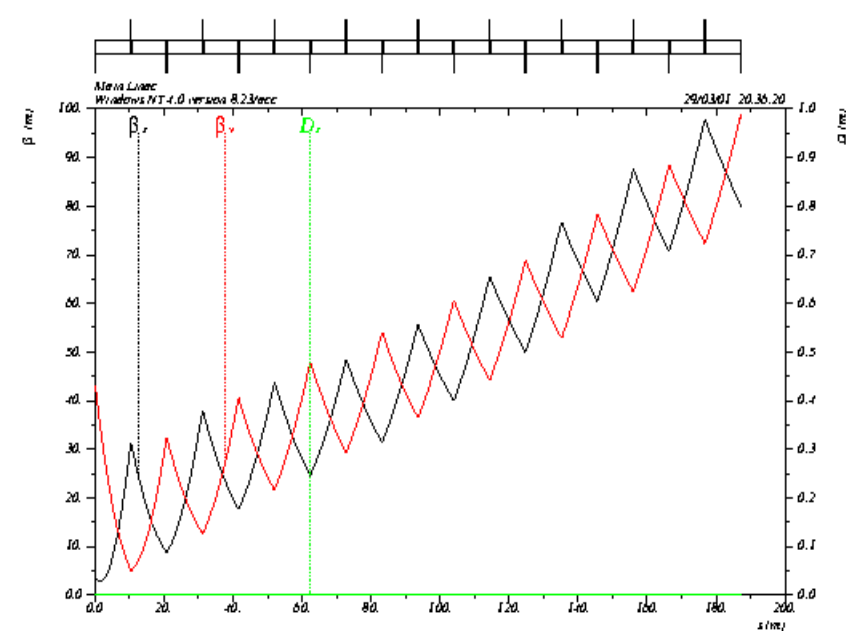

Figure 2 Optical functions in the main linac.

\section{TRIPLE BEND ACHROMATS}

The optical solution for the machine is based on a triple bend achromat cell. It was chosen mainly due to the fact that it allows tunability for the compression/ decompression of the beam. This is done by changing the dispersion function in the middle dipole with a set of quadruples between dipoles. Four such cells can form a second order achromat if one would satisfy phase advance condition [3]. Table 1 presents a basic parameter set, including phase advances for the triple bend achromats used in the layout. We use four types of those cells. The very compact design of the low energy arc provides a very limited tunability of the $\mathrm{R}_{56}$ and has no space for the insertion devices. Nevertheless, those $6 \mathrm{~m}$ cells have the required compression, good control of the $\beta$-functions and form a second order achromat in the horizontal plane.

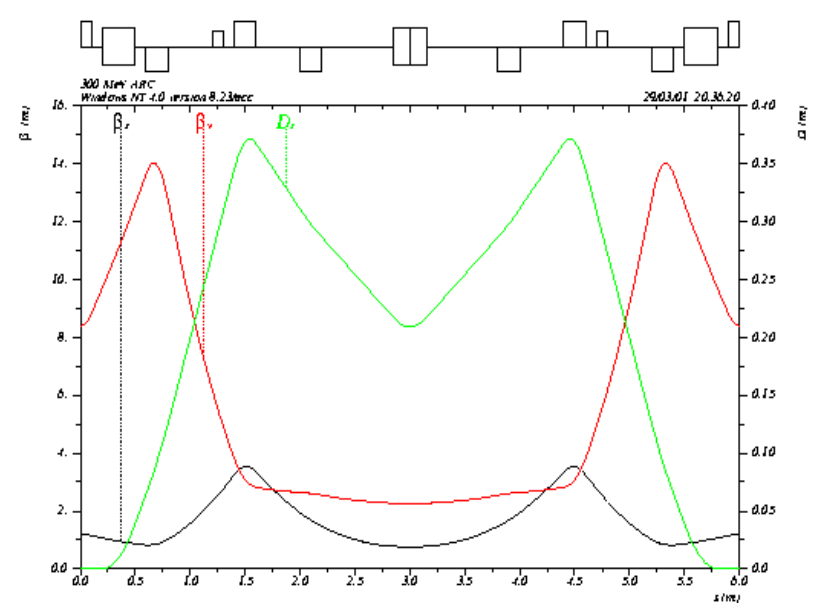

Figure 3 Optical functions of the small arc cell

\section{Table 1 Basic set of parameters for triple bend} achromat cells

\begin{tabular}{|l|c|c|c|c|}
\hline & \multirow{2}{*}{$\begin{array}{c}\text { Small } \\
\text { arc cell }\end{array}$} & \multicolumn{3}{|c|}{ Large arc cells } \\
\cline { 3 - 5 } & & $\begin{array}{c}\text { No } \\
\text { compr. }\end{array}$ & Unity & $\begin{array}{c}\text { Minus } \\
\text { unity }\end{array}$ \\
\hline Length [m] & 6 & 20 & 20 & 30 \\
\hline Phase adv. $v_{\mathrm{x}}$ & 0.75 & 1.5 & 1 & 1.5 \\
\hline Phase adv. $v_{\mathrm{y}}$ & 0.25 & 0.9 & 0.9 & 0.9 \\
\hline $\begin{array}{l}\text { Compression } \\
\mathrm{R}_{56}[\mathrm{~cm}]\end{array}$ & 6 & 0 & 3.5 & 3.5 \\
\hline $\begin{array}{l}\text { Bending angle } \\
\text { [deg] }\end{array}$ & 45 & 22.5 & 11.25 & 11.25 \\
\hline
\end{tabular}

The second type of the triple bend achromat cells is used in the first 4 cells, that form a 90 degree bend in the large arc. These cells are isochronous by design, since we postpone compression to the shortest beam. The reason for this approach is to limit the possible degradation of the beam due to various coherent effects in the small aperture insertion devices and bending magnets [4]. All cells in the large arc have $6 \mathrm{~m}$ straight dispersion free drifts for the insertion device.

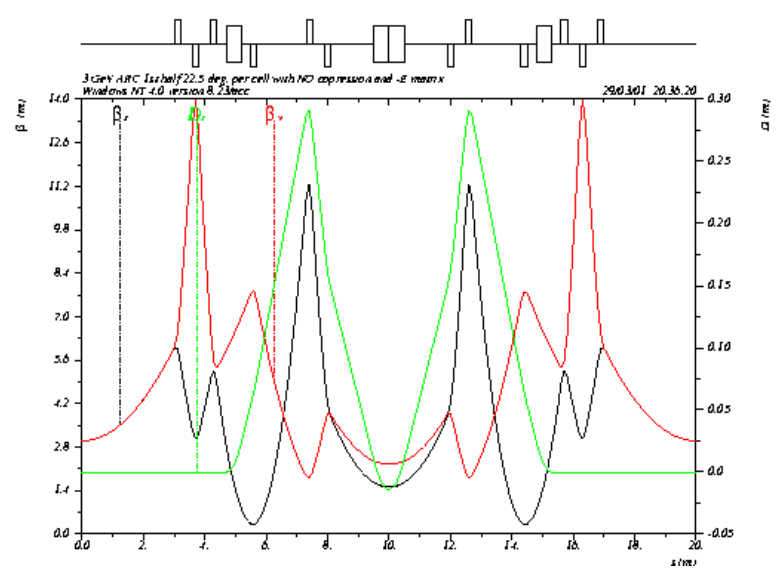

Figure 4 Optical functions of the no-compression cell in the large arc. 
Quadrupoles between dipoles have wide tuning range of the beam compression and quadrupoles outside of the dipoles provide an adjustment of the tune phase advance to accommodate phase requirement for second order achromat condition. Same considerations applies to cells type number 3 and 4 with only difference that both those types of cells perform uniform beam compression over the second ninety degrees of the large arc. The second half of the large arc starts with four cells of type 3 and continues with 4 cells of type 4 . The difference between those types of cells is the increased phase advance due to increased length of the cell type 4 . This allows to have a minus unity transport matrix of the cell to gain some compensation of emittance and energy spread degradation in the dipoles due to Coherent Synchrotron Radiation [5]. We like to use the shorter cells of the type 3 in the part of the arc where the beam is not strongly compressed yet and CSR effects are not so important. That was done to conserve some space.

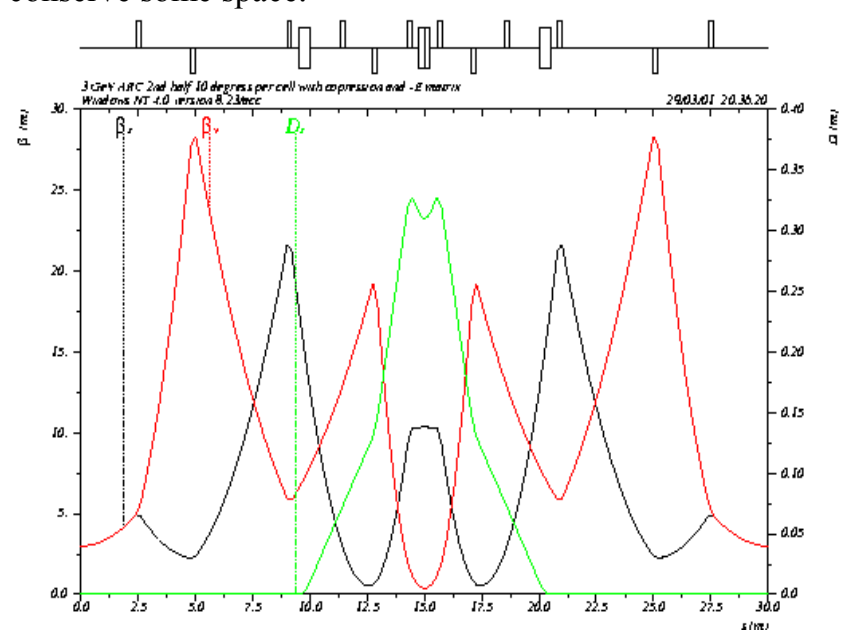

Figure 5 Optical functions in the compression cell of the large arc with "minus unity" transport matrix.

\section{LONGITUDINAL DYNAMICS}

The proposed design is symmetrical around the middle point of the long straight section. The beam gets compressed starting from the bunch length of the $\sigma_{\mathrm{RMS}}=4$ ps after the injector at $25 \mathrm{MeV}$ to $100 \mathrm{fs}$ at $3 \mathrm{GeV}$ in the long drift. The decompression of the beam will happen in the return path to accommodate the gained energy spread in the insertion devices and bending magnets. The Table 2 presents longitudinal evolution of the beam during compression and decompression. It does not show any degradation of the coherent effects specific to such a short beam. We expect that those effects would lead to increase of the longitudinal emittance and as result the bunch length would be compress to the $100 \mathrm{fs}$.

Table 2 Longitudinal phase space evolution

\begin{tabular}{|l|c|c|c|c|}
\hline & $\begin{array}{c}\text { Energy } \\
{[\mathrm{GeV}]}\end{array}$ & $\begin{array}{c}\text { Pulse } \\
\text { lengt } \\
\mathrm{h} \\
{[\mathrm{ps}]}\end{array}$ & $\begin{array}{c}\text { Uncorel } \\
\text { energy } \\
\text { spread } \\
{[\%]}\end{array}$ & $\begin{array}{c}\text { Corelate } \\
\text { d energy } \\
\text { spread } \\
{[\%]}\end{array}$ \\
\hline Injector & 0.025 & 3 & 0.09 & 0 \\
\hline $\begin{array}{l}300 \mathrm{MeV} \\
\text { linac }\end{array}$ & 0.3 & 3 & 0.008 & 0.25 \\
\hline Small arc & 0.3 & 0.4 & 0.06 & 0.2 \\
\hline Main linac & 3 & 0.4 & 0.006 & 0.046 \\
\hline Large arc & 3 & 0.05 & 0.05 & 0 \\
\hline Long drift & 3 & 0.05 & 0.05 & 0 \\
\hline Large arc & 3 & 0.4 & 0.006 & 0.046 \\
\hline Main Linac & 0.3 & 0.4 & 0.06 & 0.2 \\
\hline Small Arc & 0.3 & 3 & 0.008 & 0.25 \\
\hline $\begin{array}{l}\text { 300 MeV } \\
\text { linac }\end{array}$ & 0.025 & 3 & 0.09 & 0 \\
\hline
\end{tabular}

\section{CONCLUSION}

We have straw-man optic design for a $3 \mathrm{GeV}$ light source based on an energy recovery linac. This layout allows us to compress bunches down to $100 \mathrm{fs}$ in two stages with negligible degradation of the transverse and longitudinal emittances due to CSR and other coherent effects. The longitudinal compression was checked and corrected using the MAD tracking module with RF cavities support. The improvement steps included: optimised energy correlation vs. $\mathrm{R}_{56}$, harmonic cavity and most importantly -- use of the second order achromat in the horizontal plane for the compression arcs.

\section{REFERENCES}

[1] I. Ben-Zvi, et. al., Photoinjected Energy Recovering Linac Upgrade for the NSLS, Proceedings of the this conference.

[2] E.T. d'Amica, G. Guiguard, PRL ST Vol.4 2001

[3] Karl Brown, Roger Servranckx, NIM A258 (1987), 480-502

[4] J.B. Murphy et. al., Beam Dynamics for a Photoinjected Energy Recovery Linac at the NSLS, Proceedings of the this conference.

[5] J.H. Wu, et. al., Coherent Synchrotron Radiation Analysis for the UVFEL and Photoinjected Energy Recovery Linac Projects at the NSLS, Proceedings of this conference. 